\title{
ASPECTOS DO AMOR EM CAMILO: DA HEROÍNA ROMÂNTICA À MULHER COMUM
}

Paulo Fernando da Motta de Oliveira ${ }^{*}$

\section{A obra de Camilo Castelo Branco: algumas constantes}

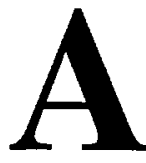

pós um conjunto de obras que ficaram esboçadas ou por se completar, e de alguns folhetos de pequeno fôlego, Camilo Castelo Branco lança, em 1851, a sua primeira grande novela, Anátema. Deste momento até o de seu suicídio, quase quarenta anos depois, em 1890, seguirá escrevendo ininterruptamente, e acabará por publicar mais de cem livros. Nesta vasta obra podemos detectar algumas linhas principais.

De início devemos salientar que, como bom romântico, Camilo transformará a sua acidentada vida em literatura. É uma constante em sua produção romanesca a presença de referências autobiográficas, como ocorre, por exemplo, no quarto capítulo de Amor de Salvação, em que tece considerações sobre o fim de seu amor por Ana Plácido', ou no prefácio à segunda edição de Amor de Perdição, em que fala sobre o seu sofrimento quando esteve preso, e do sofrimento ainda maior que tem no momento então presente ${ }^{2}$. Também podemos encontrar várias obras de Camilo em que sua vida, ou a de seus amigos, é o tema central, de que são bons exemplos Memórias do cárcere, No Bom Jesus do

* Universidade Federal de Minas Gerais.

1 Cf. CASTELO BRANCO, Camilo. Amor de salvação. Rio de Janeiro: Ediouro, s.d. p. 21-22.

2 Id., Amor de perdição, São Paulo: Queiroz \& Filhos, 1900. p. 4-6. 
Monte e Correspondência epistolar, esta última publicada em 1874 e composta por uma coleção de cartas que havia trocado com seu então já falecido amigo, e primeiro biógrafo, Vieira de Castro. Em vista disto Camilo se transforma em um eu que se lamenta através de seus livros, um eu que encontramos disperso e sempre presente no meio das milhares de páginas que escreveu. Assim, não é de estranhar que um de seus primeiros biógrafos, Alberto Pimentel, inicie o seu Romance do romancista afirmando:

Isto que vai ler-se é o drama de uma alma superior, em grande parte extraído dos seus próprios livros. (...) O mesmo é ler este escritor que coordenar mentalmente o romance de sua existência. O que eu fiz apenas foi dar à emoção produzida pela sua obra a fixação cronológica de uma biografia. ${ }^{3}$

Se esta tendência biográfica percorrerá o conjunto da produção de Camilo, podemos também nesta obra encontrar algumas outras tendências significativas, emolduradas por dois momentos bastante específicos, que marcam o início e o final de sua carreira de novelista. No início, período que vai aproximadamente de 1851 a 1855 , publica basicamente novelas folhetinescas, como o citado Anátema além de outras como Mistérios de Lisboa e O livro negro de Padre Diniz. Após este momento inicial, se excetuarmos as obras de cunho mais biográfico, podemos encontrar basicamente três tendências fundamentais em sua produção: a novela humorístico-satírica, de que são bom exemplos Coração, cabeça e estômago e A queda de um anjo; a novela passional, que tem como mais famoso exemplo Amor de perdição, mas que envolve obras tão várias como Agulha em palheiro e $O$ esqueleto; e a novela histórica, entre as quais podemos encontrar, por exemplo, $O$ judeu e $O$ regicida. No fim de sua carreira, a partir da publicação de Novelas do Minho, que ocorreu de 1875 a 1877, Camilo adere de forma bastante crítica ao Realismo-Naturalismo.

Neste artigo pretendemos analisar justamente esta adesão crítica ao Realismo-Naturalismo, através do estudo de uma das Novelas do Minho, "Maria Moisés", publicada originalmente em 1876. Para tanto, porém, precisaremos inicialmente nos referir ao mais famoso livro de Camilo, Amor de perdição, paradigma que será em certo sentido negado em "Maria Moisés".

3 PIMENTEL, Alberto. O Romance do romancista. Lisboa: F. Pastor,1890.p.5. 


\section{O amor passional: pureza e perdição}

Jacinto do Prado Coelho em seu Introdução ao estudo da novela Camiliana considera o episódio amoroso entre Manuel Botelho e uma açoriana, nunca nomeada, presente em Amor de perdição, como um "incidente não muito concertado com o seguimento da história", já o havia afirmado. Não julgamos que assim seja, pois, como veremos, uma aproximação entre este episódio e a trama amorosa central, a de Teresa / Simão / Mariana permitir-nos-á clarificar alguns dos pressupostos básicos que enformam este livro, aspecto fundamental para o posterior confronto com "Maria Moisés".

São bastante evidentes as similitudes entre esta trama básica de Amor de perdição e a de Romeu e Julieta. Na peça de Shakespeare, como na novela de Camilo, encontramos o amor entre dois fillhos de famílias rivais; a presença de um primo que é morto pelo jovem apaixonado que, em função disto, é condenado ao exílio; e, também, a morte dos dois amantes. Se certamente não existe na peça nenhuma personagem que ocupe o papel que no livro cabe a Mariana, aspecto a que em breve voltaremos, além desta diferença, existe uma outra, significativa, que nos revela um dado fundamental deste obra de Camilo. Se Romeu e Julieta se conheceram numa festa, nela dançaram, chegaram a ter um encontro e, após se casarem em segredo, puderam consumar a sua união, nada disto existe nessa novela de Camilo. O amor entre Simão e Teresa é totalmente platônico. Se apaixonaram ao se olharem pelas janelas das suas casas, que eram fronteiriças, e durante todo o livro apenas uma vez se encontram frente a frente, e mesmo esta vez em uma noite escura, de forma extremamente rápida, sem que cheguem a trocar um único beijo. A trajetória amorosa dos dois é basicamente epistolar, através das múltiplas cartas que trocam ao longo da novela.

O amor de Mariana, este elemento novo em relação à trama básica já existente em Romeu e Julieta, também possui esta mesma pureza. Ciente do abismo de classes que a separa de Simão - devemos aqui lembrar que ela era filha de um ferrador -, Mariana torna-se, a partir do momento em que por ele se apaixona, numa espécie de criada, pronta a fazer tudo que fosse necessário para melhorar a vida de seu amado, e ligada de forma tão radical ao destino dele

4 COELHO, Jacinto do Prado. Introdução ao estudo da novela camiliana. Lisboa: Imprensa Nacional-Casa da Moeda, 1982. v. 1, p. 428. 
que, quando este é inicialmente condenado à morte, Mariana enlouquece para, quando a pena de seu amado é comutada, se recuperar da loucura e de novo poder servi-lo, até o momento em que este morre, morrendo ela junto com ele.

É a partir destes traços gerais do amor que une os três protagonistas que o encontro amoroso entre Manuel Botelho e a açoriana ganha seu verdadeiro sentido, deixando de ser uma simples digressão do narrador para se constituir em um contraste que melhor explicita as concepções presentes no romance. Como sabemos, Manuel Botelho, irmão de Simão, quando estava, licenciado do exército, estudando matemáticas em Coimbra, se apaixona por uma açoriana que era casada com um estudante de medicina. Com ela foge para a Espanha c, quando o dinheiro acaba e sua mãe não tem mais como ajudá-lo, se vê forçado a voltar a Portugal. É descoberto por um amigo de seu pai e é preso por ser desertor do exército. A açoriana aceita o oferecimento do pai de seu amante para lhe transportar até os Açores para a casa de sua mãe e, por interferência do pai, Manuel Botelho é perdoado. Assim o narrador descreve a vida dos dois amantes após o fim deste atribulado romance:

Partiu para Lisboa a açoriana, e dali para a sua terra, e para o abrigo de sua mãe, que a julgara morta, e lhe deu anos de vida, se não ditosa, sossegada e desiludida de quimeras.

Manuel Botelho, obtido o perdão pela preponderância do corregedor do crime, mudou de regimento para Lisboa, e aí permaneceu até que, falecido seu pai, pediu a baixa e voltou à província. ${ }^{5}$

A este final absolutamente prosaico, o narrador ainda acrescenta um novo dado irônico, ao comentar o que ocorreu com o marido da açoriana:

Poucas horas depois, a esposa do médico...

- Que tinha morrido de paixão e vergonha talvez! - exclama uma leitora sensível.

- Não, minha senhora; o estudante continuava nesse ano a freqüentar a Universidade; e, como tinha já vasta instrução em patologia, poupou-se à morte da vergonha, que é uma morte inventada pelo visconde de A. Garrett no Fr. Luís de Sousa, e à

5 CASTELO BRANCO, Camilo. Amor de perdiçāo, p. 227. 
morte da paixão, que é outra morte inventada pelos namorados nas cartas despeitosas, e que não pega nos maridos a quem o século dotou de uns longes de filosofia (...).

Pois o médico não morreu, nem sequer desmedrou, ou levou $R$ significativo de preocupação do ânimo, insensível às amenidades da terapêtica. ${ }^{6}$

Se aqui o narrador fala da inexistência da morte por amor será justamente esta morte o destino dos três personagens principais. Ou seja, estamos aqui diante de uma situação amorosa bastante diversa da vivida por Simão, Teresa e Mariana. Este outro amor vivido por Manuel Botelho, diferentemente daquele do trio principal, é um amor pouco profundo e sexuado, e causa apenas uma perturbação passageira. Lembremos que estamos diante de um caso de adultério, crime na época punível com o degredo, mas que, mesmo assim, findo o amor, satisfeito o desejo sexual, apenas a mulher, pivô dos acontecimentos, sofre algumas conseqüências, e mesmo ela termina a sua vida pacatamente. Manuel Botelho reintegra-se na sociedade que, por momentos, negou, e o marido de sua amante nem chega a ser afetado pela fuga de sua esposa.

Estas breves reflexões sobre este caso amoroso mostram, por contraste, que é outro o destino do amor profundo e puro. Por abalar de forma clara a sociedade, por não respeitar suas barreiras, ele é ao mesmo tempo revolucionário, subvertendo quaisquer tipos de convenções sociais, e, por ser revolucionário, impossível de ser concretizado neste mundo. Tereza, Simão e Mariana são internados fora do mundo quando se recusam a aceitar os ditames sociais que impediam o seu amor, e a sua morte final nada mais é que a consumação deste destino que já era seu no momento em que se apaixonaram perdidamente. A sociedade não pode aceitar este amor absoluto. Podemos entender assim o título do romance. $\mathrm{O}$ amor de perdição é assim definido pois, por romper todas as barreiras sociais, por se sustentar de sua própria impossibilidade de consumação, acaba por expulsar aqueles que o vivem da sociedade, condenando-os, mais cedo ou mais tarde, à morte. A pureza assim está visceralmente ligada à profundidade do amor, e o amor sexuado faz parte de uma outra esfera que, se pode chegar a causar alguma perturbação, acaba por levar as pessoas de novo a se reintegrarem no contexto social. Assim, a partir do confronto entre os dois

6 CASTELO BRANCO, Camilo. Amor de perdição, p. 227. 
tipos de amor que aqui analisamos, podemos perceber que o romance cria um vínculo visceral entre a profundidade e a pureza do amor.

Estas breves reflexões, que estão longe de esgotar os múltiplos enfoques que este livro permite, já podem, porém, servir de ponte para entendermos "Maria Moisés", em que de novo teremos um amor de perdição protagonizado por uma mulher de uma classe inferior que, como Mariana, se apaixonará por um homem que não pertence a seu mundo. Passaremos agora para esta Novela do Minho.

\section{“Maria Moisés": uma obra híbrida}

Como notou Jacinto do Prado Coelho:

Entre 1855 e 1875, em Portugal, como lá fora, o estilo de vida social modificou-se, os espíritos tornaram-se, pouco a pouco, mais práticos, menos permeáveis ao sentimentalismo. Começava a era do caminho de ferro e das ciências positivas. A Literatura evolucionava, tornando-se expressão de novas inquietações. ${ }^{7}$

Se pensarmos em Portugal, a década de 70 é paradigmática desta mudança de orientação. Em 1871 ocorrem as Conferências do Casino e Eça de Queiroz, junto com Ramalho Ortigão, publica o primeiro número de As farpas. Quatro anos mais tarde o primeiro destes escritores lançou $O$ crime do Padre Amaro na Revista Ocidental. O gosto do pública ia aos poucos se alterando e Camilo, o grande representante da fiç̧ão romântica em Portugal, não podia ficar incólume a esta mudança. Nas suas declarações sempre tendia a falar mal da nova escola, a que serve de exemplo o irônico prefácio que faz, em 1879, à quinta edição do seu Amor de perdição, em que, aparentemente se lamentando de ter florescido em um período anterior da produção romanesca, considera os romances contemporâneos, para apenas citarmos alguns epítetos, como uma literatura de prostíbulo, ou como uma carne cheia de vermes ${ }^{8}$. Mas apesar

7 COELHO, op. cit. p. 65.

8 Cf. CASTELO BRANCO, Camilo. Amor de perdiçūo. p. 1-3. 
destes vitupérios, como veremos, Camilo não deixa de ser influenciado pelo Realismo, acabando por produzir o que poderíamos considerar como obras híbridas, em que procedimentos que antes havia utilizado são ao mesmo tempo mantidos e deslocados, como poderemos agora verificar em "Maria Moisés".

Como este é um livro menos conhecido de Camilo julgamos necessário apresentar aqui as linhas gerais de sua trama.

Ela se inicia em agosto de 1813, mostrando a fuga esbaforida de Josefa de sua casa, e depois o momento em que o moleiro Luís a encontra, já morta e ensangüentada, ao lado do rio. A ação então retorna para o ano anterior, explicando os motivos desta fuga e da morte de Josefa. Ela se apaixonara por um nobre, António, que também por ela se apaixonou. Viveram, meio às escondidas, um idílio, até que Josefa descobriu que estava grávida. António, temendo que seu pai não aceitasse um casamento com uma mulher que, no conceito deste, no máximo poderia ser sua amante, tenta se casar, em segredo, com a sua amada. Não só não o consegue, como o padre a quem pediu que fizesse o casamento avisa o pai de António do ocorrido, e este vai com o filho para Lisboa e lá, em função das insistências deste em casar com Josefa, prende-o. Neste meio tempo, fingindo-se de doente, Josefa consegue ocultar a sua gravidez, até que, quando já estava totalmente desesperada, é visitada por uma mulher, empregada de um amigo de António, que diz para que ela vá para a casa deste amigo até que António consiga se livrar da prisão. Combinam para que ela fuja à noite mas, devido a sua grande felicidade e pelo susto que teve por sua mãe ter finalmente percebido que ela estava grávida, a filha de Josefa acaba nascendo. Josefa foge, mas está sem forças, e ao chegar no rio o cesto de vime em que se encontrava a filha acaba por lhe escapar das mãos, e desce pelo rio afora. Josefa desfalece, morrendo logo em seguida. $O$ berço em que estava a menina é encontrado por um lavrador, e os senhores da casa em que trabalham acabam por criá-la, dando-lhe o nome de Maria Moisés.

António, quando soube da morte de Josefa, resolveu vir para o Brasil, e aqui ficou até 1850 . Neste meio tempo os padrinhos de Maria Moisés morreram, e ela, herdeira da quinta que possuíam e de mais alguns bens, resolve dedicar-se a criar as crianças que, como ela, fossem órfăs ou abandonadas. Quando António retorna do Brasil, sem saber que tem uma filha, acaba por encontrar, na aldeia em que Josefa morava, um padre que era o possuidor do segredo: não só sabia que Josefa tinha estado grávida, como havia feito, em uma outra cidade, a última confissão da mãe de Josefa, que a havia visto fugir de casa com a criança. No final do história António vê Maria Moisés, que é idêntica à mãe, e os dois se abraçam. 
O livro termina com as seguintes palavras do narrador:

Tomás Ribeiro, com o teu coração, se tens nele uma lágrima, imagina este quadro e descreve-o, se podes, que eu não posso, nem quero, porque o último feitio das novelas é não pintar, com o colorido gótico dos românticos, os quadros comoventes que rutilam na alma a faísca do entusiasmo. Agora somente se pintam as gangrenas com as cores roxas das chagas, e com as cores verdes das podridões modernas. Nos literatos o que predomina é o verde, e nas literaturas é o podre.

Assim, se aceitarmos a palavra deste narrador, ele esvazia o sentimentalismo, mas não o substitui pela visão crua das chagas morais, que caracterizaria o Realismo em seu ponto de vista. Desta forma o novo estilo seria para ele não uma regra a seguir, mas um limite sobre o que pode ou não ser feito.

Uma breve análise da novela nos mostrará que não é exatamente este o procedimento nela seguido.

Se de início nos preocuparmos com a importância que, numa novela em que se passam 38 anos, é dada a cada um dos períodos narrados, já poderemos perceber alguns dados interessantes. Na edição que utilizei, esta obra ocupa 66 páginas. Destas, quarenta são utilizadas para narrar o período que vai de 1812 a 1813 e outras desesseis para narrar o período que vai do retorno de António ao seu encontro com Maria Moisés, período em que se passam nove dias ${ }^{10}$. Assim o conto está centrado em dois temas: o do amor proibido (primeiro tempo) e o do reconhecimento (segundo tempo). Estes dois temas ligam-se diretamente a duas constantes na obra de Camilo: o romance passional e o folhetim.

Partindo desta primeira constatação poderemos verificar que outros elementos destas duas constantes também podem ser encontrados em "Maria Moisés".

De início devemos notar que o reconhecimento não é a única característica típica dos romances folhetinescos presente nesta obra. Se pensarmos

9 CASTELO BRANCO, Camilo. Novelas do Minho I. Lisboa: Europa-América, s.d., p. 82 .

10 Quando António encontra o padre que Ihe contará o segredo, afirma para este: "(...) há oito dias que cheguei" (p. 75). Será no dia posterior a este encontro que irá até a quinta de Maria Moisés e contará a ela que é seu pai. 
que as características recorrentes do folhetim são os acontecimentos rocambolescos, recheados de peripécias, mas em que os personagens são bastante simples e que nos folhetins, muitas vezes, temos "aparições súbitas de certas personagens quase esquecidas, tanto pelo leitor, quanto pelo próprio autor" 11 , poderemos verificar que "Maria Moisés" possui algumas destas características.

A grande maioria dos personagens é extremamente simples - , só encontramos alguma complexidade em Josefa e em sua mãe, Maria da Laje. Os demais podem ser definidos por poucos traços, em especial Maria Moisés e António. Ela, a bondade que chega quase à tolice (no conto ela é algumas vezes enganada na sua ânsia de ajudar os outros ${ }^{12}$ ), ele, alguém que sobrevive à morte do seu amor, mas que se mantém fiel a este amor durante 37 anos.

Temos nesta novela, também, a recuperação de um personagem quase esquecido, o padre, que, por uma sucessão de acasos, é o detentor da verdade que permite o reconhecimento. Ele havia aparecido rapidamente no início do conto, para só reaparecer quando conversa com António.

Mas a estrutura folhetinesca é nesta novela bastante simplificada. Se no folhetim clássico tem uma sucessão de acontecimentos, nos mais diferentes lugares, ligados por situações que beiram o inverossímil, aqui temos uma ação única, que se passa quase que totalmente em uma aldeia portuguesa. Mesmo as terras distantes e exóticas, características também dos folhetins, são aqui transformadas no Brasil, onde Antônio vai afogar suas dores, um espaço totalmente anexado à estrutura social e cultural portuguesa.

Por outro lado, o amor proibido aparece tanto na relação Josefa/António, como é reproduzido em uma outra, em que Joaquina, filha do lavrador que salvara Maria Moisés, também tem um filho bastardo. Mas se comparamos os amores proibidos do conto com o exemplo máximo deste amor na obra de Camilo, Amor de perdição, podemos perceber que existe uma mudança importante. Se, como vimos, na primeira obra que aqui analisamos o amor não aceito pela sociedade era um amor puro, que existia sem nenhuma manifestação carnal

11 ALVES, José Édil de Lima. A paródia em novelas follhetins camilianas. Lisboa: Instituto de Cultura e Língua Portuguesa, 1990. p. 31

12 Isto pode ser verificado, de forma clara, no trecho abaixo:

"Maria, com a sua fama de santa, era havida em conta de tola pelos velhacos. A falsa piedade explorava-a. Festas de capelas, votos de missas pedidas, resplendores para uns santos, capas para outros, esmolas para entrevados de longe, esmolas para aleijados que iam a caldas e ao mar, esmolas para rapazinhos que iam para o Brasil, para cabaneiros a quem o incêndio devorou a choça - com verdade ou impostura -, ninguém ia da sua porta com as mãos vazias.". CASTELO BRANCO, op. cit., p. 65-66. 
(lembremos que apenas o amor não profundo, o de Manuel Botelho, era impuro), aqui existe uma junção entre amor verdadeiro e sexo. Existe assim um esvaziamento da idealização que caracterizava o amor profundo, que se aproxima nesta novela mais do amor habitual: o acontecido com Joaquina é apenas um exemplo de muitos que ocorrem na aldeia, e existem no livro, para confirmar isto, inúmeras referências feitas a mulheres perdidas e a filhos abandonados por uma série de personagens ${ }^{13}$. Assim, apesar do grande amor que une António / Josefa, o caso específico da filha bastarda nascida de um amor não consagrado pela Igreja é algo comum. Os dois, neste aspecto, deixam de ser seres especiais e passam a ser pessoas comuns. Ou seja, Mariana, o protótipo da heroína romântica, aqui se transforma em Josefa, uma mulher igualmente possuidora de uma paixão avassaladora, mas que é uma mulher comum.

Uma das propostas do Realismo era justamente esta: deixar de tratar de seres especiais e falar do comum dos homens. Assim, Camilo acaba por incorporar, sem fugir a uma das tendências de sua obra, o amor passional, esta característica. $\mathrm{O}$ amor verdadeiro perde a pureza que o caracterizava em Amor de perdição, para se transformar num amor mais usual e, por isto, possível de ocorrer a qualquer um.

Devemos também notar que até mesmo a tendência autobiográfica, uma das constantes na obra camiliana como acima apontamos, não está totalmente ausente deste conto. Se não temos um narrador que a todo momento faz referências a si, o próprio tema geral da bastardia é claramente fruto de uma referência pessoal, Camilo também é, em certo sentido, um bastardo, sendo inclusive este um tema recorrentemente utilizado na obra camiliana ${ }^{14}$. Não por acaso devemos notar que a filha bastarda, Maria Moisés, possui todas as características positivas, gastando a sua parca fortuna com os menos afortunados, enquanto que as filhas legítimas, as irmãs de António, rezam por sua morte para que possam herdar os vínculos que lhe pertencem ${ }^{15}$. A bastardia se transforma, assim, nesta novela, em uma característica positiva, que dá ao indivíduo uma visão menos interesseira da vida. Devemos inclusive notar que em alguns momentos, o narrador ironiza a pureza do sangue ${ }^{16}$ e mesmo a

13 Cf. Novelas do Minho I. op. cit, s.d. p. 64 e 70

14 Cf. COELHO, Jacinto do Prado. op. cit. v. 1, p. 37.

15 "As irmãs (de António), casadas com pequenas legítimas, assim que chegavam navios brasileiros com a notícia das febres devastadoras, sentiam um vago contentamento na hipótese de ser Deus servido levar-lhes o mano general". CASTELO BRANCO, op. cit., p. 66

16 Id, p. 33-34. 
manutenção da virtude acima de tudo ${ }^{17}$, que seriam o inverso da bastardia. Ou seja, mesmo esta tendência recorrente da obra de Camilo neste livro aparece em embrião.

Em síntese, podemos dizer que Camilo trabalha com os mesmos materiais que, recorrentemente, utilizou na sua obra. Apenas tende a tirar deles o caráter excepcional - lembremos aqui que uma das características do Romantismo era justamente a de tratar de seres especiais - e inseri-los em um contexto de maior normalidade. $\mathrm{O}$ que conta poderia acontecer em qualquer aldeia portuguesa, em que um fidalgo fosse além do simples interesse passageiro por uma mulher de posição social inferior. Esta normalização é acentuada pela cena inicial de "Maria Moisés", em que são retratados de forma veraz os habitantes da aldeia, com suas crenças e costumes, como já o havia notado Jacinto do Prado Coelho ${ }^{18}$. Não temos seres excepcionais, nem casos assombrosos, mas, estruturalmente, temos ainda procedimentos que claramente são herdados do Romantismo, junto com uma recusa de tratar do abjeto e do vil, que, de fato, é típica de certa corrente do Realismo-Naturalismo. É, como afirmamos no início, uma obra híbrida, que sabe se aproveitar de características românticas e realistas para, mantendo-se fiẻl as tendências da obra de Camilo, ao mesmo tempo atualizá-las em função do novo gosto literário que então existia.

\section{RESUMO}

Este artigo pretende analisar o papel do amor em duas obras de Camilo Castelo Branco - Amor de Perdiçāo e "Maria Moisés" - e refletir sobre o estatuto híbrido desta última obra, em que convivem certos procedimentos recorrentes na produção de Camilo Castelo Branco, com outros que caracterizam a problemática adesão deste autor ao Realismo-Naturalismo.

Palavras Chaves: Camilo Castelo Branco, Romantismo, Realismo-Naturalismo

17 Id. p. 44-45.

18 Cf. COELHO. op. cit. p. 120. 


\section{ABSTRACT}

This paper intends to analyze the characteristics of love in two of Camilo Castelo Branco's works - Amor de perdiçāo and "Maria Moisés" -, and to think about hybrid status of the last one, in which we can recognize some usual Camilo's wrinting strategies and some others, that can be related with the problematic choice of Realism-Naturalism of this writer's.

\section{REFERÊNCIAS BIBLIOGRÁFICAS}

ALVES, José Édil de LimaA paródia em novelas folhetins camilianas. Lisboa: Instituto de Cultura e Língua Portuguesa, 1990.

CASTELO BRANCO, Camilo. A Queda de um anjo. Porto: Anagrama, s.d. . Agulha em palheiro. Rio, Saraiva, s.d. . Amor de perdição. São Paulo: Queiroz \& Filhos, 1900. . Amor de salvação. Rio de Janeiro: Ediouro, s.d. . Anátema. Lisboa: Livros Horizonte, 1981. . Coraçāo, cabeça e estômago. Lisboa: Europa-América, s.d. . Correspondência epistolar. Lisboa: Parceriantónio Maria Pereira, 1903. . Memórias do cárcere. Lisboa: Europa-América, s.d. . Mistérios de Lisboa. Porto: A. R. da Cruz Coutinho, 1978. . No Bom Jesus do Monte. Porsto: Chardron, s.d. . Novelas do Minho. Lisboa: Europa-América, s.d. p. 82. . O esqueleto. Lisboa: Parceria António Maria Pereira, 1902. . O judeu. Lisboa: Companhia Editora de Edições Ilustradas, s.d.

1924. . O livro negro de Padre Diniz. Lisboa: Parceria António Maria Pereira, . O regicida. Lisboa: Parceria António Maria Pereira, 1925.

COELHO, Jacinto do Prado. Introdução ao estudo da novela camiliana. Lisboa: Imprensa Nacional-Casa da Moeda, 1982.

PIMENTEL, Alberto. O Romance do romancista. Lisboa: F. Pastor, 1890.

SHAKESPEARE, William. Romeu e Julieta. In: . Tragédias. São Paulo: Melhoramentos, 1969. p. 133-248. 